\title{
EVOLUCIÓN HISTÓRICA Y DESARROLLO PROFESIONAL DE LA ENFERMERÍA EN CHILE ${ }^{1}$
}

\author{
Carmen luz Muñoz Mendoza, Ximena Isla Lund. \\ Profesoras del Dpto. de Enfermería \\ Universidad del Bío-Bío, Chile. \\ Silvia Alarcón SanHueza \\ Directora del Dpto. de Enfermería \\ Universidad del Bío-Bio, Chile. \\ Correspondencia: \\ Avenida Andrés Bello S/N Casilla $N^{\circ} 447$ \\ Chillán- Chile.
}

Palabras clave: Educación comparada, historia de la enfermería.

\section{RESUMEN}

El presente artículo tiene como objetivo principal dar a conocer el desarrollo profesional de la enfermería en Chile. Para lograr esto, hemos comenzado analizando algunos aspectos sociodemográficos de nuestro país, la estructura del Sistema de Salud y finalmente, hemos buscado en sus orígenes históricos las bases de su evolución posterior, todo esto con el fin de facilitar su comprensión y de reflejar como la Enfermería ha luchado y esta luchando por alcanzar un puesto representativo en el Sistema Nacional de Salud.

No pretendemos establecer comparaciones entre la Enfermería española y la chilena, las que si bien es cierto existen, dado las diferencias culturales, sociales y económicas, creemos ante todo, que enfermería es y será por excelencia una profesión dedicada al cuidado del individuo en cada una de las etapas de su desarrollo, independientemente del medio en el que nos encontremos.

\section{NURSING IN CHILE}

\section{SUMMARY}

The primary aim of the article is to give an idea of how the nursing profession has developed in Chile. Some socio-demographic aspects together with the structure of our Health System are analysed. Its historical origins and the basis of its evolution are also considered, in order to further understand how nursing has fought and is still fighting to reach a representative place in our National Health System.

Far from us to establish comparisons between Spanish and Chilian nursing, although they exist as they also exist cultural, social and economic differences. What we mainly want to point out is that nursing is and specifically will be, a profession devoted to looking after and caring for the human being in his/her evolution and development, no matter where this evolution and development takes place. 


\section{INTRODUCCIÓN:}

Aunque la línea de discusión de este trabajo será la enfermería, consideramos oportuno dar a conocer, una serie de datos sociodemográficos, con el fin de situarnos en el contexto que conforman sus características, y así poder comprender algunos de los aspectos que a continuación determinaremos. Chile, tiene una longitud aproximada de $4.300 \mathrm{Km}$ y una anchura cuyo promedio es de $177 \mathrm{Km}$, longitudinalmente, se divide en tres regiones morfológicas: la cordillera dominante de los Andes al este, la cordillera de la Costa al oeste y el valle Longitudinal o depresión Intermedia, ubicada entre ambas cadenas.

La población total, según datos proporcionados por el Instituto Nacional de Estadística (INE), para el año 1998, era de aproximadamente 15.017.760 habitantes, con una densidad cercana a los 19 hab $/ \mathrm{km} 2$. El $90 \%$ de la población reside en la región central. La tasa de natalidad es de 18,7 por cada 1.000 habitantes.

Administrativamente, está dividida en 13 regiones, que a su vez se subdividen en 51 provincias y éstas en 342 comunas distribuidas a lo largo del país. El sistema educativo, en gran medida se basa en modelos europeos (Gran Bretaña, Francia y Alemania), aunque se ha desarrollado una tradición cultural propia que combina elementos de los diversos grupos étnicos y que fue influida por la expansión de las fronteras nacionales. El moderno sistema, tuvo sus orígenes a mediados del siglo XIX. En la actualidad, la tasa de alfabetización, es del $94,6 \%$, siendo una de las más altas de América Latina.

Ahora bien, la salud de la población es inseparable del sistema político, económico y social del país específico: nuestro sistema de salud está condicionado, en su estructura y orientación, por las mismas fuerzas sociales que determinan la estructura económica de nuestra sociedad: la salud misma es por supuesto, un subproducto del tipo de desarrollo económico y social que se ha dado en la sociedad chilena, porque es el tipo de desarrollo que altera o no nuestro ambiente de vida y el que influencia nuestra cultura y nuestras actitudes y comportamientos frente a la salud y a la enfermedad. (1)
Dentro de los factores demográfico-sanitarios que más han influido en el desarrollo de nuestra sociedad se encuentran: la velocidad de crecimiento de la población, los cambios en su estructura, concentración y migración; la disminución de la morbimortalidad, el aumento de las expectativas de vida, mejora en la alimentación, vivienda, vestuario, trabajo, descanso de la comunidad, etc.

Finalmente, si fuera necesario definir el objetivo central de este escrito, el eje que orientará todo su desarrollo, diríamos que más que la exposición de fechas históricas de una profesión dedicada al cuidado, nos interesa sobre todo, que se conozca la evolución académico profesional que ha experimentado la enfermería chilena en el último siglo.

\section{SISTEMA DE SALUD}

El Sistema de Salud chileno es mixto, es decir, tiene un sector público y otro privado. Cada persona puede elegir libremente si entrega sus cotizaciones y recibe las prestaciones de un sector $u$ otro, a su vez, ambos sectores otorgan atenciones de salud y administran su financiamiento. En términos generales, podemos decir que el Sistema de Salud contempla tres funciones básicas:

1. Normativa, de regulación, supervisión y control: se refiere a la labor de elaborar políticas y orientaciones, para así establecer normas técnicas que regulen las acciones de salud. Esta función radica en el sector público y se organiza, por un lado, a través del Ministerio de Salud, quien define, controla y evalúa las políticas, planes, normas y programas de salud, y por otro, a través de la Subsecretaría de Salud, la Secretaría Regional Ministerial y la Superintendencia de Isapres, quienes asesoran en la regulación, control y supervisión del sistema completo.

2. Administrativa: tanto en el sector público como en el privado existen instituciones que contemplan, entre sus actividades cumplir con esta función. En el sector público, el Fondo Nacional de Salud (FONASA), es quien, administra los recursos, identifica los beneficiarios, es decir, aquellos que por ley, cotizan el $7 \%$ de sus ingresos y, los que sin aportar, son incluidos en este sistema. Además de realizar estas actividades, FONASA, es responsable de gestionar los beneficios de sus afiliados a través de dos modalidades: 
a) Modalidad de libre elección: permite a sus afiliados elegir libremente el profesional de su preferencia, ya sea del área pública o privada. FONASA financia parte de esta atención, dependiendo del grupo al que pertenezca el afiliado de acuerdo a sus ingresos: (100\% del valor en el caso A y B, $75 \%$ en el grupo C y $50 \%$ en el grupo D).

b) Modalidad Institucional: el afiliado acude a los establecimientos que pertenecen al Sistema Nacional de Servicios de Salud y es atendido por los profesionales que trabajan en dichos centros, y al igual que en el caso anterior FONASA, financia parte de la atención de acuerdo al grupo al que pertenezcan los afiliados.

Por otro parte, en el sector privado, son las Instituciones de Salud Previsional (ISAPRES), quienes administran el financiamiento y otorgan atención médica en forma directa a través de establecimientos y profesionales sanitarios particulares.

Las ISAPRES representan la apertura del sector privado en salud, que complementa al Servicio de Salud como un sistema mixto que ofrece mayores alternativas a sus afiliados, dependiendo de los recursos de cada cual. (2) En estas instituciones, los cotizantes acuerdan comprar un plan de salud, por un determinado precio; si se trata de un trabajador dependiente, este plan se financia a través del descuento por ley, del $7 \%$ de sus ingresos, a esta cantidad, el afiliado podrá añadir una cantidad de dinero adicional y voluntaria, para acceder a un mejor plan de salud, por su parte, las ISAPRES, tienen la obligación de cubrir todas las atenciones de salud que se consideran en el arancel de FONASA.

Con el objetivo de fiscalizar y regular el correcto funcionamiento de este sistema, se crea en el año 1990 la Superintendencia de ISAPRES, organismo que garantiza que se respeten plenamente los derechos de los beneficiarios establecidos en las leyes y en los contratos de salud pactados.

3. Prestaciones de salud: se efectúa a través de distintas instancias, dependiendo, por supuesto, del sector al que tengan acceso las personas. En el sector público, las prestaciones están por un lado, en manos de los hospitales e institutos, que corresponden a centros de atención secundaria y terciaria, es- tos dependen de los Servicios de Salud, y están destinados a realizar actividades de recuperación, fomento, protección de la salud y rehabilitación en aquellos casos más complejos desde el punto de vista médico, que requieren de un tratamiento más largo y eventualmente una hospitalización de varios días.

Los hospitales según su nivel de atención se clasifican en cuatro tipos y atendiendo a los siguientes criterios:

a) Grado de complejidad técnica y nivel de desarrollo de las especialidades.

b) Grado de desarrollo de organización administrativa.

c) Ámbito geográfico de acción, acorde con el sistema de complementación asistencial.

d) Número de prestaciones: consultas, altas y otros.

Por otro lado, nos encontramos, con los Consultorios Generales: Urbanos y Rurales, que junto a las Postas y Estaciones Médico Rurales corresponden a establecimientos de atención primaria, que dependen de sus respectivos municipios, tienen a su cargo la satisfacción de las necesidades básicas de salud de la población, dentro del territorio del Servicio de Salud respectivo. Ofrecen atención ambulatoria de nivel primario y sobre el medio ambiente, en distintos grados de complejidad, atienden a los diferentes sectores de la población.

En el Sector privado las prestaciones de salud están a cargo de Clínicas, Centros médico, entre otros. (3)

\section{Revisión Histórica de la enfermería}

En sus más remotos orígenes, dar cuidados, cuidar, era una actividad ligada a cualquier forma de vida, y proporcionar cuidados puede considerarse inseparable de la noción de supervivencia de los seres humanos, de la continuidad de la vida en grupo, de su desarrollo y mantenimiento. En este sentido, cuidar es conservar la vida, asegurando la satisfacción de un conjunto de necesidades indispensables para la vida, que se manifiestan de diferentes maneras, según los grupos y civilizaciones (4). Tales actividades eran realizadas, generalmente, por religiosas, cuyo sentido a la hora de proporcionar los cuidados, era no sólo el ayudar, consolar y servir al prójimo, sino, además hallar a Dios en el sufrimiento y el dolor de los semejantes. 
Sin embargo, la creación de los Centros hospitalarios como instrumentos terapéuticos, el desarrollo de la práctica médica y la aparición de nuevas necesidades sociales, se constituyeron en factores determinantes para la formación de los profesionales de enfermería a fines del siglo XIX, denominada Enfermería moderna. Hasta entonces su práctica se realizaba independiente de la práctica médica y con unas connotaciones que la diferenciaban de la medicina, por una parte, la vinculación que nuestra profesión tuvo en sus comienzos con las órdenes religiosas y por otra la herencia que dejo Nightingale como una disciplina de servicio, con un código moral rígido, comportamientos y estructuras jerarquizadas que marcó a la enfermería moderna en su desarrollo. (5)

\section{EVOLUCIÓN ACADÉMICA/EDUCATIVA}

La evolución profesional de la enfermería en Chile, al igual que en la mayoría de los países del mundo, ha experimentado profundos e importantes cambios, desde una enfermería ejercida principalmente por religiosas cuya filosofía a la hora de proporcionar los cuidados era puramente de caridad y amor al prójimo, sin más objetivos que lograr la salvación del alma y expiación de los pecados, hasta hoy en día contar con profesionales del más alto nivel, cuyo quehacer se basa en sólidos conocimientos científicos, orientados a proporcionar atención integral al individuo, familia y comunidad sana o enferma.

No obstante, lograr esto, ha significado realizar un largo y lento proceso, que en Chile comienza en el año 1902, con la creación del primer curso para enfermeras a cargo del Dr. Eduardo Moor, con una duración de 3 años y sin otro requisito que poseer un auténtico sentimiento vocacional. Posteriormente en el año 1906, se funda la primera Escuela de Enfermería, no sólo de Chile sino que también de Sudamérica, en el Hospital Vicente Paul, bajo el nombre de Escuela de Enfermeras del Estado, cuyo director fue el Dr. Francisco Navarro, asistido en la supervisión por religiosas católicas.

Un hecho que sin lugar a dudas significó un importante avance para la enfermería chilena fue la creación de la Escuela de Enfermeras Sanitarias en el año 1927, bajo la organización de la Dra. Cora Mayers y que permitió explorar nuevas tendencias en el campo de la salud, principalmente en actividades de fomento y protección de la salud.

Más tarde la fusión de la Escuela de Enfermeras Sanitarias con la Escuela de Enfermeras del Estado, da origen a la hoy llamada Escuela de Enfermería de la Universidad de Chile, mediante decreto ley del 8 de marzo del año 1929. El paso de la enseñanza de Enfermería a la Universidad marcó una importante época, ya que obligo por un lado, a mejorar la formación profesional, al aumentar el plan curricular a tres años de Enfermería Hospitalaria y un año de postgrado en Enfermería Sanitaria, y por otro, elevar los requisitos de ingreso, ya no sólo bastaba con terminar la Educación Media sino que además fue necesario rendir el Bachillerato en Humanidades como prueba específica.

Hasta entonces, la dirección de las Escuelas siempre había estado en manos de médicos, hecho que nos condicionaba a recibir la formación que ellos creían conveniente, pero en el año 1944 por primera vez en la historia de la enfermería chilena, la dirección queda a cargo de las Enfermeras, lo que motivó a lograr un mayor desarrollo profesional.

En el año 1981, la Universidad de Talca comienza a impartir la Licenciatura en Enfermería a la carrera de Enfermería-Obstetricia, en un lento proceso y con la ayuda del Colegio de Enfermeras y sobretodo de la Sociedad Chilena de Educación en Enfermería, hasta lograr que las 14 Escuelas de Enfermería existentes en nuestro país cuenten con el grado académico de Licenciados en Enfermería.

Como es de suponer, la implantación de la Licenciatura, no fue paralela en todas las Universidades del país, hecho que motivó la creación de cursos de nivelación, de un año de duración, con el fin de que todos los profesionales de enfermería estuvieran en igualdad de condiciones.

La Licenciatura, ha significado para nuestra profesión la posibilidad de lograr una mayor profundización en el área de la investigación y una mejor preparación para las futuras generaciones de profesionales que deseen trabajar en el campo de la docencia, ya que ello les permite optar a otros grados académicos como el magister y/o el doctorado. No obstante, es importante señalar, que en el área 
clínica tanto los licenciados, como los profesionales de enfermería que no lo son, tienen los mismos deberes y derechos a la hora de desempeñar su rol profesional.

En la actualidad, la Licenciatura en Enfermería, contempla un plan curricular de cinco años académicos, con asignaturas de formación básica, general y profesional. Este plan de estudio, tiene como objetivo prioritario formar profesionales con sólidos conocimientos humanistas, científicos y técnicos, capacitados para proporcionar atención integral de enfermería al individuo sano o enfermo, a la familia y a la comunidad como un todo.

Por otro lado, consideramos muy importante hacer referencia a otro tipo de personal sanitario, los llamados Técnicos de Nivel Superior en Enfermería, que complementan, a los profesionales de enfermería, con el fin de proporcionar una atención de calidad al paciente. Este personal, hasta hace muy poco tiempo eran formados en los Centros Hospitalarios durante un año, actualmente, dicha formación está en manos de las Universidades privadas y Centros de Formación Técnica, cuya duración se ha elevado a tres años con el objeto de capacitarlos en aspectos teóricos y prácticos que le permitan desempeñar actividades básicas de enfermería ya sea a nivel primario, secundario y/o terciario.

Resulta significativo, también, mencionar las especialidades de enfermería, las que en su gran mayoría pertenecen al campo clínico contemplando temas tales como: Cuidados Intensivos, MédicoQuirúrgicos, Enfermería Pediátrica, Enfermería Oftalmológica, entre otras, además de ofrecer el grado académico de Magister en Enfermería con mención en Salud Pública y/o Médico- Quirúrgica.

Finalmente, a diferencia de lo que sucede en España, en Chile, la Licenciatura en Obstetricia y Puericultura (matronas) y la Licenciatura en Nutrición y Dietética corresponden a carreras independientes de Enfermería, cada una de ellas, con objetivos claramente definidos y con una duración de cinco años.

\section{DESARROLLO PROFESIONAL}

Este apartado tiene por objeto en primer lugar analizar el desarrollo de la Enfermería Hospitalaria desde una perspectiva histórico-social y en segundo lugar, el avance que supuso la Enfermería Comunitaria y los drásticos cambios introducidos en el Sector Salud en la última década y a partir de aquí tratar de explicar las posibles coordenadas de la Enfermería chilena en el próximo siglo.

Con respecto a la Enfermería hospitalaria, es importante hacer referencia, a la orientación que tienen los cuidados hospitalarios en mi país que es "el entender y atender las necesidades personales: biopsicosociales y espirituales del hombre enfermo en forma individualizada y humanística" (6).

Con esta filosofía, sobre todo, a partir de 1984 y a raíz de la implantación de una fuerte política de desarrollo económico, financiero y administrativo en los hospitales del Ministerios de Salud, se introdujeron profundos cambios en la estructura del sistema hospitalario y uno de los que más nos afectaron como profesionales, fue la desaparición del Subsistema de Enfermería, hecho formalizado, incomprensiblemente, en el Reglamento de los Servicios de Salud.

Frente a esta situación, el Colegio de Enfermeras pronosticó problemas en los hospitales tales como: decisiones diferentes para un mismo problema de enfermería; diversidad de normas y criterios de atención, desorientación por doble dependencia jerárquica del personal, en lo formal del médico y en lo cotidiano inevitablemente de la enfermera, duplicidad de funciones y vacío en otras, caos administrativo etc. (6)

Pero además, se llevaron a cabo estudios para constatar algunos aspectos organizativos en el desempeño de las funciones de las enfermeras y como estaba la situación en los hospitales. Es así, como Edith Arenas G. et al, en 1984, confeccionaron una encuesta que fue enviada a 2500 enfermeras/os pertenecientes a hospitales tipo 1 y 2 , contestando a la misma el 23,5\%, de las cuales; el 22\% afirmaban que las actividades que le consumían más tiempo, eran las realizadas a los pacientes, o sea, la mayoría de las tareas estaban ubicadas junto al enfermo; 6 de cada 10 enfermeras/ros. Esto suponía que la estructura de actividades de enfermería presentara una imagen de pirámide aplanada, lo que es positivo, pues significa que la gran concentración de profesionales de enfermería se centraba en el cuidado del paciente, que en definitiva es la razón del ser profesional. 
Pero también, otra de las conclusiones afirmaba que: existía un verdadero caos en la dependencia de la cadena de mando y con ello falta de autoridad, tanto entre los profesionales de enfermería como en los auxiliares de sala, de ahí que fuera racional y necesario que se corrigiera el problema de la inexistencia de un Subsistema organizacional que mejorara estas situaciones y paralelamente se produjeran unas políticas, criterios, normas y procedimientos comunes, con el objetivo de mejorar no sólo la calidad de la atención sino además lograr un mayor rendimiento y eficiencia de los recursos.

Todas estas consecuencias determinan en el campo de la administración moderna de los hospitales, que los profesionales de Enfermería sean los responsables directos de la identificación, organización, educación y evaluación eficiente del conjunto de actividades de atención directa, requeridas por el enfermo, usuario o cliente para su recuperación integral.

Con respecto a la evolución de la Enfermería en Salud Comunitaria, no fue paralela a la de la hospitalaria ya desde su filosofía, como también en sus objetivos, que eran claramente diferenciadores con el tipo de atención que preconizaba para la población, con enfoques de prevención, educación sanitaria, atención sanitaria a grupos vulnerables (madre y niño), control de enfermedades infecciosas, mejora del medio ambiente etc.

El año 1927 fue el origen de lo que hoy se conoce como Enfermería Comunitaria, con la creación de la Escuela de Enfermeras Sanitarias, bajo la organización de la Dra. Cora Mayers, como respuestas a las necesidades de salud de la población, debido a muy diversos factores tales como la escasez de conocimientos, de recursos humanos capacitados y de medios y tecnología adecuada para la atención de la salud y la enfermedad.

Es importante mencionar que por aquellos años, las cifras de promedio de vida en Chile eran de 25 años, actualmente la expectativa de vida al nacer ha alcanzado un promedio de 70 años (73 en la mujer y 67 en el hombre); las tasas de mortalidad infantil eran de 232 por mil nacidos vivos, en 1997 esta tasa era de 10 por mil nacidos vivos; la tuberculosis de 308 muertos por mil habitantes, las enfermedades de transmisión sexual causaban la pérdida de los niños en el claustro materno y aumentaban la mortalidad general. (Op. Cit 7)

Más adelante, en el decenio 1942-1952, la Fundación Rockefeller y el Departamento Cooperativo Interamericano de Obras de Salubridad del Gobierno de los Estados Unidos en convenio con nuestro Gobierno, hizo posible la creación de las Unidades Sanitarias en áreas urbanas marginales y rurales en cinco ciudades del país. Esto significó desde su creación contar con modernas estructuras físicas, equipamientos, transporte, financiamiento y política de salud, orientada a resolver problemas de salud de la población, organizadas sobre las bases locales y operando en la vecindad de los usuarios y sus necesidades (Op. Cit 7).

En ese mismo decenio, la Fundación Rockefeller, Fundación Kellog y el Gobierno de los Estados Unidos, concedieron becas a enfermeras chilenas, en las áreas de Educación y Salud Pública, quienes a su regreso promovieron profundos cambios en la educación en enfermería, incorporando en el programa básico la filosofía y conceptos de salud pública, a fin de formar una única profesional con capacidad para que desempeñase eficientemente en el área Hospitalaria y Comunitaria (7).

Como queda reflejado en lo anteriormente dicho, podemos afirmar que esta época fue la de mayor auge de la Salud Pública llevando consigo la formación de la Escuela de Salubridad de la Universidad de Chile, lo que permitió la formación de profesionales altamente calificados en esta especialidad. A su vez las enfermeras de Salud Pública alcanzaron una importante posición en el orden profesional y económico.

Finalmente la decisión adoptada por los países miembros de la OMS en Alma Atta (1978), de "dar salud para todos en el año 2000", produce un nuevo enfoque que modificará los Servicios de Salud y las funciones de las enfermeras, para así cubrir las necesidades de salud de nuestras comunidades presentes y futuras.

\section{PROYECCIONES A FUTURO: CAMPO OCUPACIONAL}

En la actualidad la enfermería chilena orienta su acción a un gran número de actividades, ya sea en el sector público (hospitales, consultorios generales: urbanos y rurales) o en el privado (clínicas, in- 
dustrias, ISAPRES, etc.), desempeñando funciones asistenciales, de docencia, administración e investigación. Sin embargo, es quizás, en el sector privado donde enfermería a alcanzando importantes logros, ejemplo de esto, lo constituye las prestaciones de salud domiciliaria, sean estas exclusivamente particulares o subvencionadas por FONASA. Las singularidades de esta atención permite dar respuesta a las necesidades de salud actuales de la comunidad, al mismo tiempo que, para enfermería supone un nuevo desafío ya que le exige estar en permanente evolución profesional e intelectual. (8)

Si bien es cierto, la salud es un derecho que la persona adquiere desde antes de nacer hasta la muerte, ello no significa que el profesional de enfermería, pueda hacer valer su trabajo, lo que para nada atenta contra su calidad humana ni profesional.

En definitiva, lo importante es definir claramente cuál es la contribución de enfermería en el campo de la salud con el fin de no seguir siendo consideradas sustitutos de otros, sino hacer uso de los deberes y privilegios que históricamente ha otorgado la sociedad a nuestra profesión y de los conocimientos y capacidades para prestar una asistencia profesional de calidad. (9)

\section{CONCLUSIONES}

La Enfermería chilena, como queda de manifiesto, a lo largo de este artículo, ha experimentado profundos e importantes cambios, considerando que en sus orígenes esta práctica se basaba sólo en un conocimiento empírico y con objetivos puramente religiosos. Hoy en día, podemos decir, que lo que era una simple práctica, se ha convertido en una profesión, que cuenta con profesionales del más alto nivel, que fundamentan todo su quehacer en sólidos conocimientos científicos, técnicos y humanistas, orientados a satisfacer las necesidades de salud de la población, en las diferentes etapas de la vida. Sin embargo, somos conscientes, que aún nos queda un largo camino por recorrer, lo que hace necesario tener el valor y la fuerza suficiente para lograr que enfermería alcance el desarrollo profesional que le corresponde.

\section{AGRADECIMIENTOS:}

En primer lugar quisiera agradecer a Doña Elisa Cartagena de la Peña profesora titular de Enfermería Médico- Quirúrgica, de la Escuela de Enfermería de la Universidad de Alicante, España, por su sabiduría e incondicional apoyo.

Al Dr. Miguel Richart Martínez, Catedrático de la Escuela de Enfermería de la Universidad de Alicante, España y profesor titular de la asignatura de Metodología de la Investigación por su asesoramiento en la elaboración de este artículo.

Al Departamento de Enfermería de la Universidad de Alicante por el apoyo y la constante motivación para llevar a cabo cada uno de los proyectos emprendidos.

Al Departamento de Enfermería de la Universidad del Bío-Bío, Chile y cada uno de nuestras colegas por su apoyo y confianza, sin los cuales no habría sido posible realizar este artículo.

\section{BIBLIOGRAFÍA}

1) San Martín, H. et al. (1996) Salud, Sociedad y Enfermedad. Editorial Ciencia, Madrid..

2) Damilano, M. (1985) Rol de las Enfermeras en las ISAPRES. Rev. Colegio de Enfermeras. Chile; Enero, Febrero y Marzo; 51-52.

3) Ministerio de Salud de Chile. (1999) Manual de Programas Sociales de Salud.

4) Colliere, M.F. (1992) Promouvoir la Vie: de la Pratique des Femmes Soignantes Aux Soins Infirmiers. Intereditions, París.

5) Schneider, J; Stiepovich, J; Alves, C; Valenzuela, S. (1996) El Nacimiento del Hospital y de la Enfermería Moderna. Rev. Horizonte de Enfemería. Chile; Vol. $7 \mathrm{~N}^{\circ}$ 2; 35-41.

6) Arenas, E; Cornejo, E; Gûdelhoefer, E; Oye, C; López, I. (1982) Enfermería Hospitalaria en Chile. Rev. Colegio de Enfermeras. Chile; Enero, Febrero y Marzo; 20-28.

7) Pincheira, S. (1982) Evolución de la Enfermería en Salud Comunitaria y su Repercusión en el Desarrollo de la Enfermería. Rev. Enfermería. Chile; Año XVII No 73, Julio, Agosto y Septiembre; 32-34.

8) Alegría, P; Sáez, M. (1985) Atención de Enfermería Domiciliaria. Rev. Colegio de Enfermeras. Chile; Enero, Febrero y Marzo; 29-35.

9) Espinoza A; Peake, G; Cartes, A. (1985) Planteamientos Doctrinarios y Políticos de Acción Futura en Enfermería. Rev. Colegio de Enfermeras. Chile; Enero, Febrero y Marzo; 3-12. 